\title{
¿Convergencia o divergencia? Tensiones alrededor de los procesos de trabajo en el diario La Nación (2009-2013)
}

\section{Convergence or divergence? Tensions around the working processes in the newspaper La Nación (2009-2013)}

ARTÍCULO

\author{
Lorena Retegui \\ Universidad Nacional de Quilmes, Argentina. \\ Contacto: retegui.Iorena@gmail.com
}

Recibido: agosto de 2017

Aceptado: octubre de 2017

\begin{abstract}
Resumen
En el presente artículo analizamos los principales aspectos del proceso de convergencia de redacciones (papel y online) que se puso en marcha en el diario La Nación durante el período 2009-2013. Entendemos que no se logró la sinergia anunciada por la empresa, más allá de los cambios vividos en los procesos de organización del trabajo en el contexto de la digitalización. A partir de una investigación de corte cualitativa, centrada en entrevistas en profundidad y la observación directa en la redacción del tradicional diario, reflexionamos sobre la apropiación que hicieron de ese proceso los periodistas de una y otra plantilla, específicamente entre redactores y editores.
\end{abstract}

Palabras Clave: procesos de trabajo; convergencia; digitalización; redacciones.

\begin{abstract}
In this article we discuss the significant aspects of the newsroom convergence process (paper and online) that was launched in the newspaper La Nación, during the period 2009-2013. We understand that the synergy announced by the company was not achieved, despite the changes experienced in the processes of work organization in the context of digitalization. From a qualitative research, focusing on in-depth interviews and direct observation in the newsroom of the traditional newspaper, we will reflect on the appropriation that made journalists that process, specifically among editors and publishers.
\end{abstract}

Keywords: working processes; convergence; digitalization; newsroom.

\section{Introducción}

El objetivo de este artículo es analizar el llamado "proceso de convergencia de redacciones" puesto en marcha por el diario La Nación durante el período 2009-2013. Entendemos que hubo una etapa de avance, estancamiento y retroceso sobre el proyecto de redacción multiplataforma que excedió a los cambios tecnológicos e industriales vividos en las industrias culturales en los últimos años y se vinculó también con la organización productiva y del trabajo y las culturas profesionales de papel y online. Así también como se 
relacionó con la inmadurez del modelo de negocio en la prensa online y su consecuente incertidumbre en los ingresos.

Este artículo forma parte de una investigación más amplia, ya finalizada, que se propuso analizar las transformaciones en los procesos de organización del trabajo de periodistas, diseñadores gráficos y fotógrafos en la redacción de La Nación, donde compartieron espacio físico la plantilla de trabajadores de papel y online. A nivel metodológico se escogió un abordaje de corte cualitativo, basado centralmente en entrevistas semi-estructuradas y en profundidad y en jornadas de observación directa en la redacción. ${ }^{1}$

La Nación se caracteriza por su extensa trayectoria. Fundado en 1870 por el ex presidente Bartolomé Mitre es uno de los diarios más antiguos que circulan en el mercado argentino y con un peso simbólico muy importante: por allí circularon reconocidos e influyentes personajes de la literatura, la historia y la política. A su vez, se caracteriza por marcar agenda en el sistema de medios argentinos, tanto desde sus páginas impresas como desde la web, y por ser un diario moderno en relación al producto y a nivel tecnológico (Alonso, 2007). La Nación fue pionero en lanzar la web en 1995 y erigirse como uno de los portales líderes en habla hispana (Albornoz, 2007).

En 2009 la empresa apostó a la sinergia de redacciones (online y papel), que hasta ese momento estaban separadas físicamente, convirtiéndose en el primer diario de alcance nacional en apostar a la convergencia junto al diario Clarín. En 2013 la empresa se mudó del histórico edificio de calle Bouchard. ${ }^{2}$ Esa reorganización no implicó sólo un desplazamiento físico, sino que atravesó los procesos productivos al interior de la redacción, al afectar el desarrollo de las tecnologías de la información y la comunicación, su adopción y sus usos. Las transformaciones que inició La Nación hace cuatro años, y que al día se encuentran en plena transición, ${ }^{3}$ tienen de fondo varias aristas: una reconversión digital, una economía todavía incierta, conflictos laborales y una certeza de parte de los directivos de no volver al modelo de la "convergencia de redacciones".

\footnotetext{
${ }^{1}$ El artículo forma parte de un capítulo de la tesis doctoral, financiada por CONICET y con asiento en la UNQ. Intitulada "Los procesos de organización del trabajo en una redacción de diario en el contexto digital. El caso La Nación (1995-2013)" tiene como principal referencia teórica la Economía Política de la Comunicación (EPC). El estudio se basó principalmente en las técnicas de investigación de entrevistas de tipo semi-estructuradas y en profundidad y en la observación in situ de los procesos de trabajo al interior de la redacción. Se realizaron en total 49 entrevistas a diferentes actores involucrados en los procesos de trabajo y se hicieron cinco jornadas intensivas de observación participante durante los meses de mayo y junio de 2013.

2 En el edificio de Bouchard al 500, entre Viamonte y Tucumán, La Nación estuvo desde 1969, año en que mudaron primero las rotativas. En enero de 1980 se hizo el traslado completo. Allí, los periodistas vivieron cambios tecnológicos importantes como la transición del plomo al offset, del télex al fax, de la máquina de escribir a la computadora. En septiembre de 2013 se hizo la mudanza a un moderno edificio en Vicente López

${ }^{3}$ Este artículo no analizará en profundidad el escenario post convergencia de redacciones, sino que se enfocará en el trabajo de campo del periodo 2009-2013, cuyos resultados forman parte de la tesis doctoral de la autora.
} 


\section{Redacciones (des)integradas}

Existe consenso entre los entrevistadosde que la cultura del periodismo online y las tecnologías convergentes "vinieron para quedarse". Pese a ello, y aunque en 2009 desde la empresa se anunció con exaltación el paso hacia una redacción multimedia (Roitberg, 2009) no se logró un proceso de sinergia de plataformas y redacciones.

En el momento del lanzamiento, la disposición de los trabajadores se hizo de modo tal que redactores de la web se ubicaron en forma intercalada junto a redactores del diario. "Eso duró muy poco porque había mucha resistencia de la gente de papel" reconoció Graciela, delegada gremial del diario (2013). En sintonía, Juliana (2015) brindó un ejemplo de lo que pasó durante ese período:

En 2009 bajamos con la idea de converger, no sucedió. Nunca se terminó de entender bien el plan que tenían. En un primer momento dos chicos de economía online se mudaron a la zona de Economía de papel. Era el primer gran avance, pero la realidad es que al lado tenían a un desconocido. Alguna que otra nota le pidieron pero del otro lado, nada y regresaron porque no sumaba. Para nosotros de online es muy difícil tener a una persona de nuestro equipo a 25 mesas de distancia sobre todo para los editores que tienen que poner todas las notas en home. Si bien tenemos el chat interno, no es lo mismo (Juliana, redactora online, 2015).

Al no funcionar esa disposición de periodistas intercalados, en 2011 se decidió ubicar a la redacción web en el núcleo de la redacción, en la zona "caliente", rodeados de todas las secciones de papel, del departamento de arte, de fotografía y de las oficinas de los secretarios de redacción; esa ubicación se mantuvo hasta el cierre de estudio. En las siguientes páginas abordaremos las principales conclusiones del trabajo de campo que nos permiten sostener que, durante el periodo de estudio, hubo más una coordinación de soportes aislados que una integración plena.

\subsection{No ayudarás a tu prójimo}

Durante el periodo 2009-2013 no se conformó una mesa central de trabajo conjunto entre la web y papel y si bien se crearon nuevos roles para la implantación de la convergencia, como la función del secretario de multimedia, cada editor fue responsable de los contenidos de su plataforma. Los editores de papel y online no se reunieron habitualmente para intercambiar ideas, ofrecer material, planificar coberturas conjuntamente o repartir el costo de proyectos especiales y en los pocos casos en que se realizó fue producto de la predisposición individual y no de un trabajo en equipo. Por otro lado, no hubo entre periodistas de diferentes plataformas ningún tipo de sinergia que sí se pudo observar entre redactores de distintas secciones del papel. Citas como las siguientes se repitieron en la redacción: 
La convergencia acá es incompleta. No está formalizada. Tenemos redactores que escriben para el online y otros que no; información del online que viene al papel y otra que no; es caso por caso. Creo que el proyecto apuntaba a algo más integrado pero no es lo que ocurre hoy en día (Felipe, jefe editor de política, 2013);

Cuando llegué en 2011 estaban completamente separadas, en el mismo piso pero no había rastros de esa convergencia. Lo que vi es que no teníamos casi interacción con la gente de papel y se hablaba por lo bajo de la convergencia fallida. En general, el periodista de papel considera a la web como algo inferior. Es insólito que en esta época que estamos viviendo [los de papel] se crean más periodistas que nosotros. En cinco años más quiero ver de qué van a estar laburando (Manuel, subeditor de online, 2015).

En sintonía con estas declaraciones, un alto mando de la gerencia reconoció en off que la convergencia directamente no existió. Por un lado, sostuvo que acomodar las rutinas de los periodistas, diseñadores y fotógrafos no fue sencillo y no se logró ese proceso, aunque consideró que se avanzó mucho respecto a lo que ocurría en La Nación hace 15 años, donde las secciones del papel trabajaban en forma aislada y eran más "cerradas". Por otro lado, la misma fuente reconoció que editorialmente "se podrían tomar decisiones en torno del online hacia el papel que hoy no se toman", y como ejemplo lanzó la utilización de tecnologías digitales durante las reuniones de temario y de tapa. "Se sigue trabajando como si únicamente existiera el papel", se quejó el entrevistado.

Los siguientes testimonios remarcan que hubo desde el primer momento una competencia solapada entre ambas redacciones con divergencias en la organización del trabajo:

Llamás a una fuente y te dicen: ya hablé con fulanita de online y vos ni te enteraste. $\mathrm{O}$ te mandan a cubrir la costa durante el verano pero no tiene sentido porque también mandan a tipos de online que hacen todo: hacen la moda en la playa de Pinamar y hacen a un candidato que te cuenta: "ya vino un pibe de online y me entrevistó" y le ofrecen el video que es más atractivo. Tenés la competencia afuera y adentro (Ignacio, redactor de política, 2013);

Si vos estás trabajando todo el día, tenés que cerrar y no confirmás que Bergoglio votó a Menem, online te lo tira, sin mucha profundidad y todo tu laburo de ocho horas no sirvió. Hiciste todo para darle una idea a un tipo. Entonces, qué pasaba: nos mentíamos entre los editores para no darle temas a online (Mario, ex subeditor de política, 2012);

Esa convergencia falló, nunca pasó de ser una cuestión discursiva y que nos pusieran a todos en el mismo piso, principalmente porque nunca dejó de haber una guerra fría entre papel y online. A mí me pasó que me publicaran notas en papel (que también salieron en online) y al otro día tener un problema con mis jefes (Laura, ex periodista online, 2013).

Lo que podemos observar con estos testimonios es que hubo una desconfianza en el trabajo del otro y una ausencia de colaboración que cruzó tanto a los redactores como a 
los editores, y se tradujo en la falta de planificación de coberturas, el ocultamiento de temas a la otra redacción y rispideces en los casos en que un redactor escribía para una y otra plataforma. No hubo un intercambio permanente de contenidos y por ese motivo convivieron dos sistemas de gestión de contenido, uno para papel y otro para online. En la redacción papel utilizaban al momento de cierre de este estudio un sistema internacional, el DTI, mientras que en la web se utilizaba otro tipo de publicador, el CMS. ${ }^{4}$

Sí tenemos que destacar que hubo gestos de colaboración con trabajadores que cumplieron otro rol en la cadena productiva del diario. Por ejemplo, redactores y editores de las secciones de política y economía (papel) comenzaron a trabajar con programadores, investigadores y diseñadores web en la búsqueda, visualización y apertura de datos públicos. ${ }^{5}$

A su vez, si bien creció el interés de los periodistas de papel por publicar en online, la convivencia entre unos y otros es visualizada en términos de rivalidad:

Hay más colaboración que al principio de la convergencia pero sigue existiendo una rivalidad tal que por momentos parece que fuéramos enemigos. Creo que ocurre como ocurre con todo lo que es nuevo, donde hay algunos que son "aguante la tecnología" y están los reticentes. Hoy por qué sigue existiendo cuesta entenderlo. Sobre todo papel es más reticente con online que al revés. Online es más piedra en el zapato (Antonia, editora de fotografía en online, 2013);

Fue un intento fallido. Eso no era convergencia, era aprovechar recursos. Sí hubo en los últimos años un poco más de intercambio. Del otro lado hubo cada vez más interés en mostrarse en el online; se dan cuenta porque es más fácil de compartir por redes sociales, se ve más, es más fácil a estar atentos a repercusiones de tu nota, la llegada es mucho más medible (Tobías, redactor online, 2015).

Por su parte, redactores del online hacen hincapié en "prejuicios infundados" hacia el trabajo del otro que llevó a la escasa colaboración entre ambas redacciones:

Surgieron trabas desde la jerarquía, incluso de gente del diario que había propuesto la integración, digamos que desde la empresa misma retrocedieron con la idea. A eso se le suman los celos y la falta de apertura tanto de un lado como del otro. Hay prejuicios infundados: los de papel dicen que los de online no saben hacer periodismo; los de online que los de papel son lentos, que son vagos, porque "se toman todo un día de cobertura para escribir 20 centímetros" (Rafael, ex editor en online, 2013);

Está el que se copa porque le interesa el lenguaje y le interesa aprender pero también hay mucho celo de que nosotros le vayamos a sacar el puesto, hay mucho

\footnotetext{
${ }^{4}$ El Digital Technology International (DTI) es un programa de proveedor externo que reemplazó al Quark Press en 2003 en La Nación; incorpora los programas InDesigne In Copy de Adobe, utilizados por diseñadores y periodistas, respectivamente. El programa Content Manager System (CMS) permite crear, editar y publicar en el sitio web.

${ }^{5}$ En 2012 La Nación lanzó el proyecto piloto llamado "data", que permite visualizar diferentes indicadores; una plataforma de datos abiertos para que el usuario pueda utilizarla de manera interactiva.
} 
comentario de que somos ignorantes, que no somos periodistas. He leído que nosotros tenemos que cobrar menos que ellos, que están de acuerdo con que tengamos menor salario porque tenemos menos contactos que ellos. También pasó que venga un vocero y te diga: me pide $X$ de papel que no hable con online. Es cierto que nosotros trabajamos con otro nivel de profundidad y muchas veces es otro lenguaje, es más la lógica de la inmediatez de la radio. Y así va mutando el periodismo en general. El diario de registro hoy ya no te sirve (Tobías, redactor online, 2015).

En el caso de los diseñadores no mantuvieron políticas de colaboración con sus pares de la web. Según lo observado y las respuestas de los entrevistados, la organización del trabajo, las economías de tiempo y las cualificaciones son diferentes y eso dificulta el cruce entre ambas plantillas. "Hoy en día no hay mucha vida en común porque somos dos mundos, pero todo conduce a que la forma de diseñar será otra cosa. No sé cuándo pero el oficio del diseñador que conocemos va a desaparecer", señaló Cecilia (2013).

\subsection{Resistencia a la polivalencia}

Un concepto que está vinculado con el surgimiento del periodismo online y la multiplicación de plataformas es el llamado periodista multitarea o polivalente porque no sólo escribe su nota, sino que obtiene fotos, videos, utiliza recursos gráficos y herramientas web con el objetivo de que las producciones sirvan para diferentes medios. Se trata de un proceso que, según Mosco (2006), lleva a que los periodistas actúen cada vez más bajo los roles combinados de editor y productor. "Esta habilidad de eliminar trabajo, combinarlo para que efectúe múltiples tareas y trasladarlo a los consumidores, que no son pagados por ello, expande mucho más el potencial de las ganancias" (Mosco, 2006).

Si bien con el lanzamiento de la convergencia de redacciones el discurso empresarial fue la polivalencia como meta, y en esa línea hubo capacitaciones para todos los trabajadores, lo que se pudo observar fueron experiencias aisladas en papel y una polivalencia resistida, incluso en la redacción web. De todos modos, hay un consenso entre los actores de que la multifunción y la sobrecarga de trabajo terminará primando en una industria que en los últimos años redujo su mano de obra.

Esas experiencias aisladas de polivalencia se llevaron a cabo en un clima de desconfianza, de reclamos por las condiciones laborales ya que se hicieron más flexibles a partir de la concreción de varias tareas por trabajador y de resistencia hacia la incorporación de ciertas tecnologías como los celulares smartphone, las cámaras digitales, un mayor uso de Internet y de plataformas de redes sociales. Esto ocurrió, principalmente, al momento del anuncio de la unificación de redacciones. 
Pedro (2013) reconoció que llegó a tomar imágenes antes de irse del diario porque no lo mandaban con fotógrafo. "El periodismo multitarea existe, aunque te lo regulen con los sindicatos", aseguró el ex periodista. Gerónimo (2013), en cambio, aseguró que eso dependerá de la resistencia que ejerza el periodista. "Yo siempre me negué y jamás se publicó una nota con una foto mía", asegura. Para Diego "depende del redactor", aunque reconoció que es una situación cada vez más difícil de evitar. "Es lo mismo que si nosotros saliéramos con la cámara y, de paso, hiciéramos la nota. Me parece una locura pero la realidad es que todo va hacia ese camino".

Uno de los rechazos a la polivalencia fue la falta de retribución económica. Clara, que está en el diario desde 1990, indicó al respecto:

A mí me interesa hacer el online pero para hacer el doble trabajo por la misma paga me quedo en mi casa y hago algo que redunde más. Si me lo pagan como colaboración, fantástico, me rompo el alma para hacerlo, además es algo que me divierte. Pero no por el mismo sueldo (Clara, redactora de política, 2013).

Para Antonia (2013), en su rol de fotógrafa, y para Laura (2013) como ex redactora de online la polivalencia deriva en la falta de calidad en el producto:

Acá salimos con capturas, yo me resisto pero a veces me gana la información y entonces se prioriza la rapidez por sobre la calidad. En online es goodenough. Para ello te enseñan a ser periodista multitarea: acá todos saben cortar una foto, editar un video, embeber de las redes sociales. El gran problema es que con captura de pantalla también salen en el papel o con fotos de celular que son un desastre y me da bronca porque ellos sí tienen tiempo. Y los propios fotógrafos te dicen: "la acomodo un poquito, la pongo a dos columnas y sale igual" (Antonia, editora de fotografía de online, 2013);

Para mí es un delirio y no hay que aceptarlo [la polivalencia]. Pero el pedido de la empresa está. El mensaje es "ustedes chicos tienen que saber que cuando salen a la calle...". En el último tiempo, yo titulaba, yo subía la foto, yo la cortaba y tuve errores como subir una foto mal cortada y tener conflictos por eso. Ahora un editor de foto pero en algún momento no hubo (Laura, ex redactora online, 2013).

Por su parte, Isabel, editora de papel (2013), puso el foco en un déficit de gestión del online y en un choque de culturas dentro de la redacción que expone la desconfianza en la calidad del trabajo del otro:

Creo que es un déficit de gestión periodística del online. Hay que pensar periodísticamente el online, no es solo subir rápido y poner videítos [...] Los que trabajamos en el diario papel, lo tomamos como un apéndice medio raro, al que a veces tenemos que ir a corregir [...] Hay jerarquías dentro de la redacción: no es lo mismo trabajar en política que en el suplemento volante, de la misma manera que uno de política papel considera colega a uno de economía, pero a online no le pasas una primicia porque no hacen el diario que nosotros hacemos, porque se confunde 
la habilidad tecnológica, o ser "nativo digital", con saber periodismo, y no es lo mismo. Los chicos también tienen que aprender a hacer periodismo y no hay nadie que los guíe (Isabel, editora redacción papel, 2013).

\section{3 ¿Política de web first?}

Como señala Díaz Noci (2015), la proporción de noticias que se crea específicamente para la web y luego se publica en la versión impresa está creciendo cuando hasta hace relativamente poco tiempo la edición en papel marcaba la pauta. Sin embargo, la política de "primero en Internet" duró sólo un tiempo en el periodo de estudio. Tuvo un alto impacto al inicio de la llamada convergencia de redacciones y luego se disipó tanto en el mensaje de editores como en la práctica. El web first dependió de la temática y de la posibilidad o no de reservarse la exclusiva. En las jornadas de trabajo de campo se observó que en ciertas ocasiones quedaba en la opción del editor y del redactor la política de web first y no era material que se pusiera en discusión en las reuniones de temario. Así lo manifestaron algunos entrevistados:

Si bien se ha impuesto el web-first, cuando hay hechos que son exclusivamente primicia, se deja para el papel. De hecho, si bien estamos juntos en el piso todavía no se ha dado una fusión completa de lo que es una redacción multiplataforma (Eugenio, secretario de redacción, 2013);

Es un proceso que nunca terminó de cuajar. Al principio cuando se empezó a trabajar en el mismo piso se abrió el web-first. En la práctica no sucedió: "Esto sí usalo para el online; pero esto no. Porque esto mañana va a ser la diferencia nuestra en el diario; esto sí ponelo porque sale dentro de 10 minutos en otro portal" (Emilio, editor de Economía, 2013).

Rafael (2013) resaltó que hay resistencia de que el online obtenga primero el dato, a pesar de que hoy la primicia "es efímera" y el miedo de periodistas del papel a perder su nicho, su especialización:

Con el tema del paro de colectivos de la UTA, a las 12 de la noche seguían en conciliación. La edición de papel cerró con que seguía el paro y estaban negociando. A las 2 de la mañana un gremialista me manda un mensaje y me dice: levantamos el paro. Lo primero que hice fue avisarles a los de online porque para papel nos queda viejo; a mí me nace porque conozco el otro lado. A su vez, en el papel, hay gente que tiene determinados nichos, el mío es el gremial. Yo no puedo enojarme si un periodista del online llama a [Hugo] Moyano. No me puedo enojar pero hay otros que se enojan (Rafael, ex redactor online, 2013).

\section{4 [Nuestras] economías de tiempo}

Más allá de los cambios que introdujo el contexto de la digitalización, el diario sigue teniendo un único cierre. En la web, en cambio, desaparece la hora de cierre porque hay una alta rotación del ciclo productivo que se asemeja a la lógica de flujo, propia de otras industrias culturales como la televisiva o la radial. Esto afectó, según coinciden los 
entrevistados, en la dinámica diaria. Para muchos, la velocidad con la que trabajan en el online, y que fue aumentando en los últimos años, conspiró contra una sana convivencia con papel. Entendemos que esas economías de tiempo se acercaron cada vez más a una meta del "0 Stock de Tiempo" (Roldán, 2010 y 2011). ${ }^{6}$

"Si en el papel parás, entre las 14 y las 15, no pasa nada pero en online no podés estar sin una hora de actualización”, explicó Tobías (2015). Si bien hay tiempos estrictos en la cadena de producción de un diario (cronometrados en las rotativas porque el diario pierde valor económico en 24 horas) esa característica de lógica estandarizada es difícil aplicarla de la misma manera en la redacción. También lo es en online ante noticias de último momento o situaciones aleatorias, pero los horarios de ingresos fueron estrictos y controlados, al igual que la renovación de las publicaciones, cada vez más exigente, que derivó, según los testimonios, en una sobrecarga laboral, escenario cuestionado no sólo en papel sino también en la propia redacción digital.

Otros testimonios hicieron hincapié en las dificultades que tienen en realizar trabajo fuera de la redacción para cumplir con las economías de tiempo. Citas como la siguiente fueron reiteradas:

Online es como un trabajo de oficina, no salís demasiado a la calle. Si hay una marcha en la 9 de julio, no podes ir y escribir cuando volvés, entonces lo tomás de la tele y si requerís más información, tomás un teléfono. Te quema mucho la cabeza. Terminás muy agotado. Los días en que no pasa nada a nivel noticia, aprovechás a hacer producción propia y vas manejando tus tiempos, pero a diferencia del diario papel los tiempos son mucho más cortos, decimos que tenemos un cierre durante 24 horas (Sebastián, ex redactor online, 2013).

De todos modos, creemos que la modalidad in house, que muchos entrevistados cuestionaron, es constitutivo a una decisión empresarial que decide producir puertas adentro y ahorrar en costos (de viáticos, de recursos humanos) y no está vinculado necesariamente a una cuestión de meta de O Stock de Tiempo. Esto nos enlaza en el último rasgo que analizamos: una, todavía, economía incierta para las empresas editoriales en el contexto digital.

\subsection{Un negocio vacilante}

\footnotetext{
${ }^{6}$ El 0 Stock de Tiempo es una categoría utilizada en la tesis que refiere a una variante de los mecanismos de coordinación y control de trabajo (Código del Trabajo), que retomamos de las investigaciones realizadas por la socióloga argentina Martha Roldán $(2010,2011)$. El cero stock es propio del modelo toyotista que propugna el cero stock de insumo, cero stock de errores, cero stock de tiempo en toda la cadena de producción, por ejemplo de la industria automotriz. Pues bien, en las industrias culturales no es posible aplicar todos los elementos de control. En nuestro caso de estudio lo que observamos fueron plazos máximos para producir que definimos como 0 Stock de Tiempo.
} 
Con el trasfondo de una caída en la venta de diarios, cada vez más fuerte, ${ }^{7}$ y de apertura de retiros voluntarios (muy acentuada desde el año 2011), la empresa La Nación navegó, durante el periodo de estudio, entre la incertidumbre que generó (y genera) el modelo de negocio de la web y la incertidumbre de cuándo el papel dejará de ser la nave insignia, la vaca lechera de la compañía.

Ese panorama alentó a la empresa a probar cómo trasladar la cantidad de visitas de la web en inversión publicitaria. De ese modo, a partir de 2009 se colaron los sistemas de métricas en la redacción, a partir de un software que mide, incluso en tiempo real, la cantidad de clics por nota, tiempo de lectura, porcentaje de clics acumulados, entre otros parámetros. ${ }^{8}$ Aunque monetizar ese tráfico fue y es complejo, el objetivo del Departamento Comercial de La Nación es claro: capitalizar el "stock" de mediciones para "vender" audiencia. Este mecanismo generó tensiones en ambas plantillas que percibieron cómo se incorporaba a sus procesos de trabajo lo que Boczkowski y Mitchelstein (2013) denominaron "la tiranía por el clic":

Hay algo que hace el periodismo siempre que es combinar lo interesante con lo importante, pero nosotros tenemos que decirle al lector algunas cosas que quizás no son divertidas, pero es muy importante que lo conozcan. Hay que equilibrar entre darle al lector lo que interesa y lo que necesita saber. En el papel está mucho más equilibrado; se nos sigue pidiendo el periodismo desde que se inventó el periodismo, pero al inicio de la convergencia hubo un boom por llevar a la tapa aquellas notas que más clic tenían y en un momento eso se sobrestimó y se perdió la brújula (Isabel, editora en papel, 2013).

Para llevar a cabo esa decisión que describe la editora en la cita precedente, La Nación incorporó editores SEO, ${ }^{9}$ encargados de optimizar el tráfico hacia la puntocom y aconsejar y controlar que los redactores y diseñadores produzcan en función de los clics e implementen estrategias tendientes a lograr que las notas sean indexadas por buscadores como Google. Esos mecanismos de coordinación y control para que utilicen las métricas generaron tensiones al interior de la redacción. Seleccionamos las siguientes citas que contraponen la mirada de un editor de la web (SEO) y la de un redactor:

Se sabe cuántas notas hizo cada periodista por día, si rindieron o no. Incluso es una cosa medio lúdica: tu nota anduvo; tu nota, no. El otro día, un redactor hizo una nota sobre salud, muy bien hecha y titulada y fue la nota más visitada y lo llamé para

\footnotetext{
${ }^{7}$ Escenario que excede a la Argentina y al diario La Nación en particular. La circulación de la prensa escrita a nivel global se redujo en un $2 \%$ en 2013, respecto a 2009 a nivel global y los ingresos por publicidad bajaron en un $13 \%$ para el mismo período. Datos de: http://blog.wanifra.org/2014/06/09/world-press-trends-print-and-digital-together-increasing-newspaperaudiences

${ }^{8}$ En 2009 comenzó a utilizarse el ClickTracker y cerca del final del periodo de estudio se introdujo el software denominado Charbeat, cuyas características lo asemejan a los programas que miden el minuto-minuto de la televisión.

${ }^{9}$ Tomado del concepto inglés Search Engine Optimization.
} 
felicitarlo porque no había venido ese día a la redacción. Si es la más leída, lo felicitás.

[Pero si te hago una súper nota de producción, con fuentes, bien escrita, pero no rinde en clics. ¿Me felicitás igual?]

Y... es una lástima que hayas estado un mes trabajando en una nota que no funcionó. No me sirve. No es una buena nota (Manuel, sub-editor turno tarde, 2015);

Tuve varias reuniones porque mi productividad estaba baja y me decían: "en base a que el mes pasado publicaste tres notas de producción propia y este mes 1 ..." Y yo contestaba que la actualización me demandaba todo el día. Creo que se trata de una concepción del periodismo de unos y otros. Cómo puede ser que desde papel había editores que me estaban sondeando para que me pasara a trabajar ahí y para ellos [editores de online] tenía baja productividad (Sebastián, ex redactor online, 2013).

Este comportamiento llevado a cabo en La Nación desde 2009, pero con mayor fuerza a partir de 2011, con el objetivo de monetizar las notas online,$^{10}$ develó un escenario de constante prueba y error desde la gerencia del diario, lo cual coincidió con otras redacciones de diario donde la implementación de la sinergia se llevó a cabo "con bastante inseguridad" (García Avilés y et al., 2009). No hay que perder de vista que la economía de los medios digitales no consigue asentarse y ello repercute en las decisiones de los modos de organizar el trabajo y, en consecuencia, de las relaciones laborales dentro de la redacción.

\section{Palabras Finales}

Una conclusión obvia sería que el fracaso de la convergencia en La Nación se derivó exclusivamente de las resistencias de los trabajadores a converger. Sin embargo, una mirada más profunda nos ubica ante un escenario más complejo: hubo un proceso de avance, estancamiento y retroceso sobre el proyecto de redacción multiplataforma que excede a los cambios tecnológicos e industriales y se vincula más estrechamente con la organización laboral y las culturas profesionales, como así también con la ausencia de un modelo de negocio y la falta de gestión.

Consideramos que hubo una desconfianza mayor al inicio del proceso, en el año 2009, motivada por el pedido de la empresa de implementar la polivalencia. Hubo resistencia por parte de los trabajadores a crear material para varios medios sin que ello sea remunerado económica y simbólicamente.

Tanto a partir de las entrevistas realizadas como de las observaciones de campo se pudo comprobar que el intercambio de material con la otra redacción quedó sujeto a la predisposición individual y no a un mecanismo aceitado entre ambas redacciones. Los periodistas de la redacción papel siguieron en el proceso de priorizar más el contenido que el soporte y si bien la polivalencia arrancó siendo un requisito desde lo discursivo, lo cierto es que sólo se sistematizó entre los redactores de la plantilla web y entre los fotógrafos y no estuvo exenta de tensiones y reclamos gremiales.

\footnotetext{
${ }^{10}$ Para una revisión más completa sobre el uso de métricas en La Nación, ver Retegui (2014).
} 
La percepción que muchos periodistas tuvieron del trabajo de la otra redacción no colaboró con el proceso de convergencia; entienden que son dos culturas diferentes y apuntan a que la falta de sinergia se debió principalmente a una ausencia de dirección y de los celos profesionales entre una y otra redacción. Por otro lado, una de las situaciones que marcan los entrevistados está vinculada con la lógica de flujo que se maneja en la web y la meta de "0 Stock de Tiempo". La exigencia de tiempos cada vez más cortos para la creación y adquisición de contenidos en online conspira contra la calidad del producto y la posibilidad de realizar trabajo creativo. Esas economías de tiempo fueron, sin embargo, también cuestionadas por los propios redactores y editores web porque entorpecen lo que consideran la esencia del periodismo: salir a la calle, realizar producción propia, contactarse cara a cara con las fuentes.

En síntesis, se puede señalar que la convergencia de redacciones y plataformas en sus primeros cuatro años sólo resultó en una integración arquitectónica y el discurso motivacional de La Nación -tanto al interior de la redacción como desde sus editorialesno se tradujo en la práctica. Es decir, hubo más fragmentación y rutinas de producción disruptivas que una convergencia de redacciones. Por otro lado, si bien no fue propósito de este artículo, se puede especular con que no se desplegó una estrategia de la empresa, sino más bien fueron comportamientos que fueron mutando en un escenario de mucha prueba y error, desde 2009. Consecuencia de ello $-y$ aunque su análisis excede a estas páginas- es que desde la empresa decidieron (en agosto de 2015) relanzar la "nueva redacción", en el nuevo edificio, ubicado en Vicente López.

Por otro lado, entendemos que el proceso de convergencia digital no es solamente tecnológico y, en este marco, la fragmentación demostrada en la redacción de La Nación está vinculada no sólo a aspectos técnicos, sino también a aspectos culturales, de cómo perciben los protagonistas su propio trabajo y el trabajo del otro; del sentido que cada trabajador le da a las nuevas tecnologías a través de negociaciones, resistencias, apropiaciones, disputas en torno al mismo objeto, y del modo que internalizan patrones culturales.

En síntesis, este proceso se da en un contexto, el de convergencia digital, que se configura como una etapa de crisis envuelta en un modelo de negocio que aún no se asienta y una audiencia que migra cada vez más hacia nuevas plataformas y "lo que se pone más en crisis con la revolución digital es la manera en que se produce, edita, almacena, distribuye y consume cultura a nivel masivo" (Becerra, 2015). En ese gris se cocinó el proceso de convergencia de redacciones en La Nación.

\section{Referencias bibliográficas}

Albornoz, L. (2007). Periodismo digital. Los grandes diarios en la Red. Buenos Aires: La Crujía. 
Alonso, P. (2007). Los lenguajes de oposición en la década de 1880. La Nación y EI Nacional. En Revista de Instituciones, Ideas y Mercados 46, pp. 35-46. Recuperado de: http://www.eseade.edu.ar/files/46 2 alonso.pdf

Becerra, M. (2015). Cultura y comunicación: la revolución digital con final abierto. En Revista Anfibia. Recuperado de:

http://papel.revistafibra.info/numeros-editados/cultura-y-comunicacion-la-revolucion-digitalcon-final-abierto/

Boczkowski, P. (2010). News at work: Imitation in an age of information abundance. Chicago: The University of Chicago Press.

Boczkowski, P. y Mitchelstein, E. (2013). The News Gap. When the Information Preferences of the Media and the Public Diverge. Estados Unidos: MIT Press.

Bustamante, E. (Ed.) (2003). Hacia un Nuevo sistema mundial de comunicación. Las industrias culturales en la era digital. Barcelona: Gedisa.

De Mateo, R. y Berges, L (2011). Reflexiones sobre El proceso de câmbios en la estrutura de la industria de la comunicación y en la gestión empresarial, en Campos Freire, F. (Ed.) El nuevo escenario mediático. España: Comunicación Social, ediciones y publicaciones.

García Avilés, A.; Carvajal, M; Kaltenbrunner, A., Meier, K y Kraus, D. (2009). Integración de redacciones en Austria, España y Alemania: modelos de convergencia de medios. En Revista Anàlisi 38. Recuperado de:

http://ddd.uab.cat/pub/analisi/02112175n38/02112175n38p173.pdf

Garnham, N. (2005). From Cultural to Creative Industries. An analysis of the implications of the 'creative industries' approach to arts and media policy making in the United Kingdom. En International Journal of Cultural Policy 11 (1), 15-29.

Hernández Sampieri, R., Fernández Collado, C. y Baptista Lucio, P. (2010). Metodología de la investigación. México: McGraw-Hill Interamericana.

Martini, S. y Luchessi, L. (2004). Los que hacen la noticia. Periodismo, información y poder. Buenos Aires: Editorial Biblos.

Mosco, V. (2006). La Economía Política de la Comunicación: una actualización diez años después. En Cuadernos de Información y Comunicación 11, 57-79. Recuperado de: http://revistas.ucm.es/index.php/CIYC/article/view/CIYC0606110057A

Mosco, V. (2009). La economía política de la comunicación. Reformulación y renovación. Barcelona: Editorial Bosch, S.A.

Palacios, M. \& Díaz Noci, J. (Eds.) (2009). Ciberperiodismo: métodos de investigación. Una aproximación multidisciplinar en perspectiva comparada. Bilbao: Servicio Editorial de la Universidad del País Vasco.

Retegui, L (2014). Trabajo creativo, TIC y mecanismos de control en los procesos laborales en las industrias culturales. Un estudio de caso en Argentina. En Global Media Journal Mexico, 11(22), 20-42. Recuperado de: https://journals.tdl.org/gmjei/index.php/GMJ El/article/view/214 
Roitberg, G. (2009). La Nación estrenó su redacción integrada. La Nación. Recuperado de: http://www.lanacion.com.ar/1215826-la-nacion-estreno-su-redaccion-integrada

Roldán, M. (2011). Nueva codificación de trabajo creativo televisivo y capitalismo informacional contemporáneo. Algunas implicaciones para el desarrollo en base a la experiencia argentina. En Perspectiva Metodológicas 12.

Roldán, M. (2012). Trabajo Informático "Creativo", Códigos del Trabajo y Laboral, y Contextos Contemporáneos de Reestructuración Socioeconómica y Desarrollo. Reflexiones en la Argentina (2000s) en Congress of theLatin American Studies Association, San Francisco, California.

Zallo, R. (1988). Economía de la comunicación y la cultura. Madrid: Akal.

Zallo, R. (2011). Estructuras de la comunicación y de la cultura. Políticas para la era digital. Barcelona: Editorial Gedisa.

\section{Entrevistas}

Antonia (2013). Entrevista realizada por la autora a la editora de fotografía online de La Nación. Inédita.

Cecilia (2013). Entrevista realizada por la autora a la diseñadora gráfica de La Nación. Inédita.

Clara (2013). Entrevista realizada por la autora a la redactora de política de La Nación. Inédita.

Diego (2013). Entrevista realizada por la autora al ex fotógrafo de La Nación. Inédita.

Emilio (2013). Entrevista realizada por la autora al editor de Economía de La Nación. Inédita.

Eugenio (2013). Entrevista realizada por la autora al secretario de redacción de La Nación. Inédita.

Felipe (2013). Entrevista realizada por la autora al editor de política papel de La Nación. Inédita.

Gerónimo (2013). Entrevista realizada por la autora al redactor en papel de La Nación. Inédita.

Graciela (2013). Entrevista realizada por la autora a la diseñadora gráfica y delegada gremial de La Nación. Inédita.

Ignacio (2013). Entrevista realizada por la autora al redactor de política en papel de La Nación. Inédita.

Isabel (2013). Entrevista realizada por la autora a la editora en papel de La Nación. Inédita. Juliana (2015). Entrevista realizada por la autora a la redactora online turno mañana de La Nación. Inédita.

Laura (2013). Entrevista realizada por la autora a la ex redactora online, actual redactora papel de La Nación. Inédita.

Manuel (2015). Entrevista realizada por la autora al subeditor de online turno tarde de La Nación. Inédita.

Mario (2012). Entrevista realizada por la autora al ex redactor y subeditor de política en papel de La Nación. Inédita.

Pedro (2013). Entrevista realizada por la autora al ex redactor, corresponsal en el exterior y subeditor de La Nación. Inédita. 
Rafael (2013). Entrevista realizada por la autora al ex editor en online, actual redactor en papel de La Nación. Inédita.

Sebastián (2013). Entrevista realizada por la autora al ex redactor online, actual redactor papel de La Nación. Inédita.

Tobías (2015). Entrevista realizada por la autora al redactor online turno mañana de La Nación. Inédita. 